\title{
Electrostatic charge on a plastic spacer device influences the delivery of salbutamol
}

\author{
J.H. Wildhaber*, S.G. Devadason*, M.J. Hayden*, R. James**, \\ A.P. Dufty ${ }^{+}$, R.A. Fox ${ }^{+}$, Q.A. Summers ${ }^{++}$, P.N. LeSouëf*
}

Electrostatic charge on a plastic spacer device influences the delivery of salbutamol. J.H. Wildhaber, S.G. Devadason, M.J. Hayden, R. James, A.P. Dufty, R.A. Fox, Q.A. Summers, P.N. LeSouëf. @ ERS Journals Ltd 1996.

ABSTRACT: The aim of this study was to determine whether electrostatic charge on a plastic spacer decreases the delivery of salbutamol from a pressurized metereddose inhaler (pMDI) and, if so, to find an optimal and practical treatment to remove the charge.

Ten single actuations from a salbutamol pMDI were drawn through different Volumatic ${ }^{\circledR}$ spacers at a constant flow of $60 \mathrm{~L} \cdot \mathrm{min}^{-1}$. The efficacies of different methods of removing charge were tested, including detergent coating of the spacers. A multistage liquid impinger was used to determine the particle size distribution of the output of the pMDI through the Volumatic ${ }^{\circledR}$ spacers. The electrostatic charge on the inner surface of the spacers was measured both quantitatively with an electrometer, and qualitatively by the attraction of a thin strip of cellulose membrane to the wall of the spacer. Each experiment was repeated four times.

Ionic detergent coating of the spacers removed the charge for at least $24 \mathrm{~h}$. This resulted in an increase of $55-70 \%$ in small particle $(<6.8 \mu \mathrm{m})$ delivery compared to delivery from new spacers with high charge.

We have demonstrated that electrostatic charge plays a major role in the delivery of salbutamol through plastic spacers. Adequate treatment with ionic detergent removes the charge and improves drug delivery.

Eur Respir J., 1996; 9, 1943-1946.
*The Perth Medical Aerosol Research Group, Dept of Respiratory Medicine, Princess Margaret Hospital for Children, Perth, Western Australia. **Dept of Physics, University of Western Australia, Nedlands, Western Australia. +Dept of Medical Physics and ${ }^{++}$Dept of Respiratory Medicine, Royal Perth Hospital, Perth, Western Australia.

Correspondence: J. Wildhaber Dept of Respiratory Medicine Princess Margaret Hospital for Children Roberts Road

Subiaco 6008

Western Australia

Keywords: Aerosol therapy electrostatic charge inhalation devices

Received: November 231995 Accepted after revision April 241996
Pressurized metered-dose inhalers (pMDIs) have been used to deliver aerosols to the lower respiratory tract of patients for many years. Their widespread popularity is largely attributable to their convenience. However, the use of pMDIs is associated with a number of problems, which have limited their effectiveness. The most important problems are co-ordination difficulties, and high oropharyngeal deposition resulting from pMDI actuation directly into the mouth [1]. These problems have been greatly reduced by the development of spacer devices $[2,3]$. The main concept of a spacer device is that of a chamber reservoir, where the actuated aerosol cloud can be held prior to inhalation by the patient.

The delivery of an aerosol through a spacer device depends on many different parameters [4]. One of these is the electrostatic charge on the plastic spacer device. Recent work has suggested that the charge generated by a pMDI by itself is low [5]. However, due to the characteristics of polycarbonate chambers, considerable electrostatic charge can be induced under certain conditions. Electrostatic charge on an object may be either positive or negative, caused by frictional contact with a material of different dielectric constant [6]. The actuated aerosol may be attracted to the wall of the spacer by the electrostatic charge and, thus, retained within the chamber. Therefore, the electrostatic charge on the spacer device may influence the delivery of aerosol [7].

The aim of this study was to determine by laboratory testing, whether electrostatic charge on a plastic spacer influences the availability of the actuated aerosol for inhalation, and, if so, to find the optimal treatment of a spacer in order to minimize its electrostatic charge, to decrease the amount of drug retained within the chamber, and hence to increase the delivery of the drug.

\section{Materials and methods}

\section{Study design}

Measurement of electrostatic charge (both quantitative and qualitative) and drug delivery was carried out on the following Volumatic ${ }^{\circledR}$ spacers (Allen and Hanbury's, Australia): 1) new spacers which had been stored in their original plastic bag; 2) patients' old spacers; and 3) spacers, which were rubbed with a thin piece of clear plastic to generate electrostatic charge.

In addition, an attempt was made to remove the electrostatic charge from plastic-rubbed spacers in the following manner: 4) water-rinsed and cotton towel-dried; 5) water-rinsed and drip-dried for $2 \mathrm{~h}$; 6) covered internally with aluminium foil (to provide a conducting layer on the inner surface of the spacer); 7) treated with antistatic spray (Armor All protectant; Armor All products, USA); 8) coated with cationic detergent (Cetrimide 40\%; Princess Margaret Hospital Pharmacy, Australia); 9) 
coated with anionic detergent (Liquid pyroneg; Diversey, Australia); or 10) coated with nonionic detergent (Premium; Able Westchem, Australia).

Finally, the routine methods used by patients to clean and store their spacers were assessed by asking 29 asthmatic children and their parents in our out-patient clinic to complete a questionnaire with the following questions: How long have you had your spacer? How often do you clean your spacer? How do you clean it? Do you towel dry your spacer or allow it to drip dry? and How do you store your spacer?

\section{Methods}

The detergent coating was carried out in the following manner: 1) The spacer was immersed in diluted cationic $(1: 125)$, anionic $(1: 250)$ or nonionic $(1: 1000)$ detergent for $1 \mathrm{~h}$ and drip-dried for 2, 4, 12, or $24 \mathrm{~h}$. Detergents were diluted as recommended by the manufacturers. 2) The spacer was immersed in diluted cationic $(1: 125)$ or anionic (1:250) detergent for $1 \mathrm{~h}$, drip-dried for $1 \mathrm{~h}$ and stored either wrapped in a plastic bag or unwrapped for 1 week. 3) The spacer was washed in diluted cationic (1:125), anionic (1:250) or nonionic (1:1000) detergent and cotton towel-dried.

Electrostatic charge was assessed both quantitatively and qualitatively. Quanitative measurement of electrostatic charge on each spacer was performed using an electrometer (Model 37C; Electronic Instruments Ltd, Jacoby Mitchell, Sydney, Australia). The $35 \mathrm{cc}$ ionization chamber, normally used with this electrometer, was replaced by a metal electrode of area $20 \times 19 \mathrm{~mm}$. This had its surface insulated by a $0.8 \mathrm{~mm}$ thick piece of Teflon, so that touching a charged surface would not discharge it. The electrometer gave a reading in roentgen which could be converted into coulombs (C) using the relationship for a $35 \mathrm{cc}$ ionization chamber that 1 roentgen is equivalent to $11.7 \mathrm{nC}$. The surface charge density was calculated by dividing the measured charge by the electrode area of $3.8 \times 10^{-4} \mathrm{~m}^{2}$. For ease of comparison, surface charge density was classified into the following three categories: none (negligible charge $0-1.2 \mu \mathrm{C} \cdot \mathrm{m}^{-2}$ ); low charge $(1.2-$ $\left.3.3 \mu \mathrm{C} \cdot \mathrm{m}^{-2}\right)$; and high charge $\left(3.3-6.7 \mu \mathrm{C} \cdot \mathrm{m}^{-2}\right)$. Measurements on a charged sheet of perspex indicated that the readings were reliable provided the surface charge was low enough to avoid spontaneous discharge due to air ionization. This only appeared at charge densities above those observed in practice. The readings had no dependence on the proximity of the electrode to the charged surface provided that this was within millimetres. In addition, qualitative assessment was carried out using a thin strip of cellulose membrane $(1 \times 5 \mathrm{~cm})$. The attraction of the cellulose depended on the charge on the surface of the spacers. Using this method, the charge on the spacer surface was again classified as none, low or high.

Drug delivery through the spacers was measured by the following method. The salbutamol pMDI (Ventolin; Allen and Hanbury's, Australia) was shaken for $30 \mathrm{~s}$ and two actuations were wasted prior to testing. The pMDI was then actuated into the Volumatic $®$ spacer, which was attached to a high performance multistage liquid impinger (MSLI) (Copley, Nottingham, UK). Air was drawn through this system at a continuous flow of 60
$\mathrm{L} \cdot \mathrm{min}^{-1}$. Ten single actuations were then introduced into the spacer, with $5 \mathrm{~s}$ intervals between each actuation. The pMDI was shaken vigorously in the intervals between actuations.

After actuating the pMDI, the aerosol was drawn through the device with the entraining airflow. Droplets were deposited on the actuator, the throat or one of four stages, and the site of deposition was determined by the particle size of the droplets. The MSLI had been calibrated by the manufacturer so that particles $>13,6.8-13$, $3.1-6.8$ and $<3.1 \mu \mathrm{m}$ were deposited on stages $1,2,3$ and 4, respectively. Calibration was performed using both monodisperse dioctylphthalate (DOP) droplets produced by a vibrating orifice aerosol generator and polydisperse DOP and an aerodynamic particle sizer.

The actuator, spacer, throat and each of the stages of the MSLI were separately washed with $40 \mathrm{~mL}$ of methanol. Five millilitres of $0.1 \mathrm{M} \mathrm{NaOH}$ was added to each wash and the volume was then made up to 50 $\mathrm{mL}$ with methanol. The absorbance $(\lambda=246 \mathrm{~nm})$ of each sample was measured in duplicate on a spectrophotometer (Hitachi U-2000; Japan). The concentration of salbutamol in each sample was obtained by using the absorbance of a standard solution containing a known concentration of salbutamol. The standard curve for salbutamol was linear $\left(r^{2}=1.00\right)$ for concentrations between 0 and $21 \mu \mathrm{g} \cdot \mathrm{mL}^{-1}$. Each experiment from actuation of the pMDI to the measurements of the drug concentration was repeated four times. All measurements were undertaken under the following atmospheric conditions: mean temperature was $22.9^{\circ} \mathrm{C}$ (range $22-25^{\circ} \mathrm{C}$ ), and mean barometric pressure was $763 \mathrm{mmHg}$ (range 756-770 $\mathrm{mmHg})$.

Analysis

Statistical analysis was carried out using analysis of variance (ANOVA) (StatView 512+; Albacus Concepts Inc., CA, USA) with a significance level of $95 \%(\mathrm{p}<0.05)$.

\section{Results}

Quantitative and qualitative measurements of electrostatic charge gave concordant results for all spacers. We present the amount of drug delivered in particles $<6.8$ $\mu \mathrm{m}$ for the various spacers in tables 1 and 2 .

\section{New and patients' old spacers}

New spacers had a high electrostatic charge on their inner surface, and delivery of particles $<6.8 \mu \mathrm{m}$ was low. Patients' old spacers still had detectable charge in either the low or high range. However, the amount of drug delivered in particles $<6.8 \mu \mathrm{m}$ was higher $(\mathrm{p}<0.001)$ than from new spacers. There was no significant difference in electrostatic charge or delivery of particles $<6.8 \mu \mathrm{m}$ between new and plastic-rubbed spacers.

\section{Water rinsed}

When plastic rubbed spacers were water-rinsed and either towel- or drip-dried, their electrostatic charge was 
Table 1. - Electrostatic charge and drug delivery of particles $<6.8 \mu \mathrm{m}$ as a percentage of the total amount in different Volumatic $\circledR$ spacers $(n=4)$

\begin{tabular}{lcc}
\hline Spacers & Charge & $\begin{array}{c}\text { Drug delivery\# } \\
\%\end{array}$ \\
\hline New & High & $30 \pm 3$ \\
& & $(26-32)$ \\
Old & Low-high & $37 \pm 4$ \\
& & $(33-41)$ \\
Plastic-rubbed & High & $32 \pm 3$ \\
& & $(29-36)$ \\
Water-rinsed, towel-dried & Low-high & $33 \pm 1$ \\
& & $(32-34)$ \\
Water-rinsed, 2 h drip-dried & Low-high & $33 \pm 1$ \\
& & $(32-35)$ \\
Inside aluminium foil covered & None & $48 \pm 2$ \\
& & $(45-50)$ \\
Antistatic spray treated & None & $43 \pm 1$ \\
& & $(42-44)$ \\
\hline
\end{tabular}

\#: mean $\pm \mathrm{SD}$, and range in parenthesis.

still detectable. As the charge decreased only slightly after these treatments, there was no significant improvement in drug delivery of particles $<6.8 \mu \mathrm{m}$.

\section{Aluminium foil}

When plastic-rubbed spacers were covered internally with aluminium foil there was no detectable charge. Drug delivery of particles $<6.8 \mu \mathrm{m}$ was higher $(\mathrm{p}<0.001)$ in spacers covered with aluminium foil when compared to new, patients' old, plastic-rubbed and water-rinsed spacers. There was no significant difference in electrostatic charge or delivery of particles $<6.8 \mu \mathrm{m}$ between spacers covered with aluminium foil when compared to ionic detergent coated spacers, drip-dried for up to $24 \mathrm{~h}$ (fig. 1).

\section{Cationic and anionic detergent}

Ionic detergent coating removed the electrostatic charge from plastic-rubbed spacers for at least $24 \mathrm{~h}$. However, when spacers coated with ionic detergent were stored for

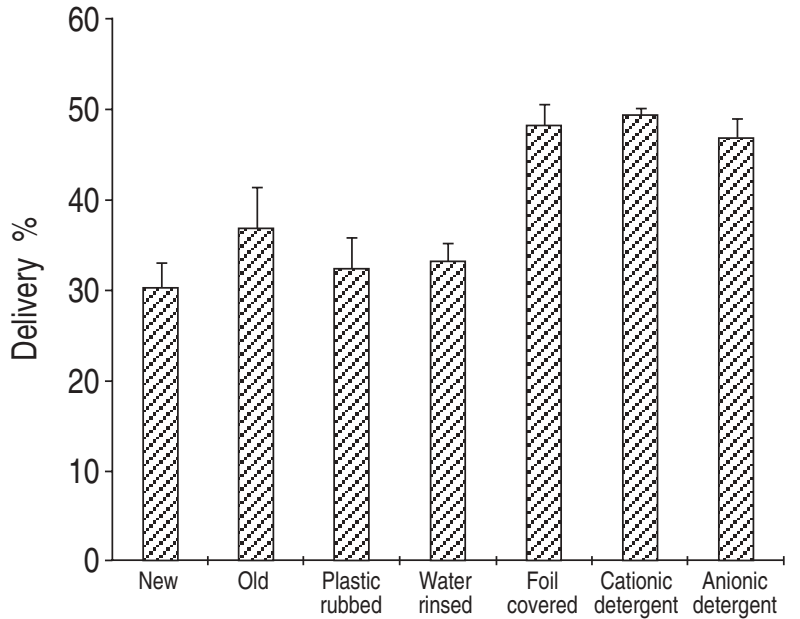

Fig. 1. - Drug delivery of particles $<6.8 \mu \mathrm{m}$ as a percentage of the total amount in spacers $(n=4)$ : new; patients' old; plastic-rubbed; waterrinsed and $2 \mathrm{~h}$ drip-dried; aluminium foil covered; cationic detergent coated and $24 \mathrm{~h}$ drip-dried; and anionic detergent coated and $24 \mathrm{~h}$ drip-dried. Values are presented as mean and SD.

1 week a low charge was detected, whether or not they were wrapped in a plastic bag. Drug delivery of particles $<6.8 \mu \mathrm{m}$ was higher $(\mathrm{p}<0.001)$ in spacers coated with ionic detergent, even when they were towel-dried when compared to plastic-rubbed spacers. However, storage for 1 week reduced the positive effect on drug delivery (fig. 2).

\section{Nonionic detergent}

Spacers coated with nonionic detergent still had a low electrostatic charge. They showed a higher $(\mathrm{p}<0.001)$ delivery of particles $<6.8 \mu \mathrm{m}$ when drip-dried for up to $12 \mathrm{~h}$ when compared to plastic-rubbed spacers. However, when drip-dried for longer than $12 \mathrm{~h}$ this effect was eliminated (fig. 2).

\section{Questionnaire}

Analysis of the questionnaire showed that spacers are used for up to $5 \mathrm{yrs}$. Our patients washed their

Table 2. - Electrostatic charge and drug delivery of particles $<6.8 \mu \mathrm{m}$ as a percentage of the total amount in detergent coated Volumatic $\circledast$ spacers $(n=4)$

\begin{tabular}{|c|c|c|c|c|c|c|}
\hline \multirow[b]{2}{*}{ Treatment } & \multicolumn{2}{|c|}{$\begin{array}{l}\text { Cationic detergent coated } \\
\text { spacers }\end{array}$} & \multicolumn{2}{|c|}{$\begin{array}{l}\text { Anionic detergent coated } \\
\text { spacers }\end{array}$} & \multicolumn{2}{|c|}{$\begin{array}{l}\text { Nonionic detergent coated } \\
\text { spacers }\end{array}$} \\
\hline & Charge & Delivery $\%$ & Charge & Delivery \% & Charge & Delivery \% \\
\hline $\begin{array}{l}\text { Detergent coated, } 2 \mathrm{~h} \\
\text { drip-dried }\end{array}$ & None & $\begin{array}{l}51 \pm 4 \\
(48-55)\end{array}$ & None & $\begin{array}{c}49 \pm 2 \\
(46-50)\end{array}$ & Low & $\begin{array}{c}44 \pm 1 \\
(44-45)\end{array}$ \\
\hline $\begin{array}{l}\text { Detergent coated, } 4 \mathrm{~h} \\
\text { drip-dried }\end{array}$ & None & $\begin{array}{l}50 \pm 1 \\
(49-52)\end{array}$ & None & $\begin{array}{c}47 \pm 1 \\
(46-47)\end{array}$ & Low & $\begin{array}{c}43 \pm 1 \\
(41-44)\end{array}$ \\
\hline $\begin{array}{l}\text { Detergent coated, } 12 \mathrm{~h} \\
\text { drip-dried }\end{array}$ & None & $\begin{array}{c}47 \pm 2 \\
(45-49)\end{array}$ & None & $\begin{array}{c}48 \pm 1 \\
(47-49)\end{array}$ & Low & $\begin{array}{c}44 \pm 1 \\
(43-45)\end{array}$ \\
\hline $\begin{array}{l}\text { Detergent coated, } 24 \mathrm{~h} \\
\text { drip-dried }\end{array}$ & None & $\begin{array}{c}49 \pm 1 \\
(49-50)\end{array}$ & None & $\begin{array}{c}47 \pm 2 \\
(44-48)\end{array}$ & High & $\begin{array}{c}37 \pm 2 \\
(35-39)\end{array}$ \\
\hline $\begin{array}{l}\text { Detergent coated, } \\
1 \text { week drip-dried }\end{array}$ & None-low & $\begin{array}{l}43 \pm 1 \\
(42-44)\end{array}$ & None-low & $\begin{array}{l}44 \pm 2 \\
(42-46)\end{array}$ & - & - \\
\hline $\begin{array}{l}\text { Detergent coated, } 1 \text { week } \\
\text { stored in plastic bag }\end{array}$ & Low & $\begin{array}{l}43 \pm 1 \\
(42-45)\end{array}$ & Low & $\begin{array}{c}44 \pm 1 \\
(42-45)\end{array}$ & - & - \\
\hline $\begin{array}{l}\text { Detergent washed, } \\
\text { towel-dried }\end{array}$ & None & $\begin{array}{c}48 \pm 1 \\
(47-50)\end{array}$ & None & $\begin{array}{c}46 \pm 1 \\
(44-47)\end{array}$ & Low & $\begin{array}{c}42 \pm 2 \\
(40-44)\end{array}$ \\
\hline
\end{tabular}

Values are presented as mean $\pm \mathrm{SD}$, and range in parenthesis. 


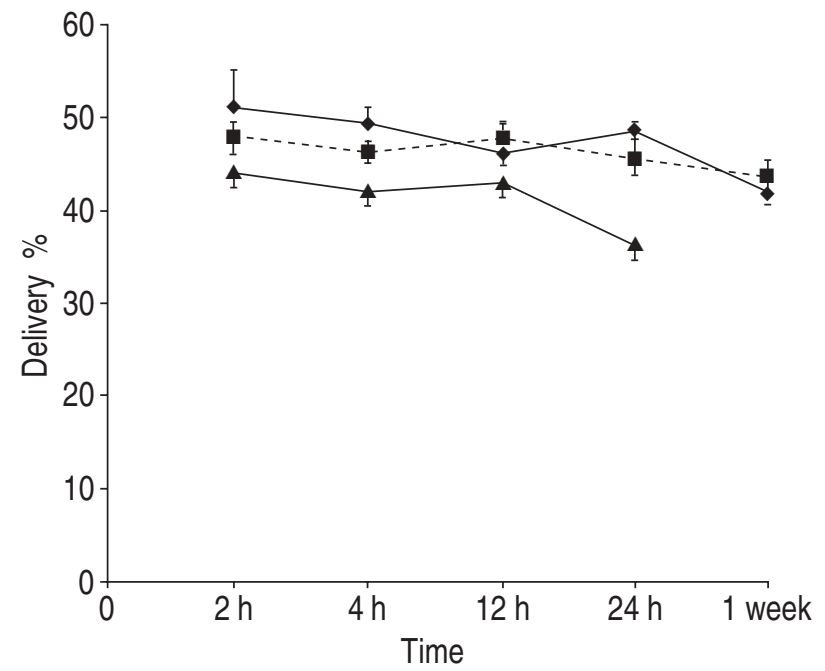

Fig. 2. - Drug delivery of particles $<6.8 \mu \mathrm{m}$ as a percentage of the total amount in detergent coated spacers allowed to drip dry for 2 , 4, 12, $24 \mathrm{~h}$ and 1 week $(\mathrm{n}=4)$. ——: cationic; - - - - - -: anionic;

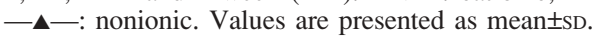

spacers at least monthly and some washed them after each use. Spacers were water-rinsed by $62 \%$ of the patients, whilst they were immersed in detergent and then allowed to drip dry by $38 \%$. Spacers were toweldried after washing by $24 \%$ of the patients. Most patients $(72 \%)$ stored their spacers unwrapped and 28\% patients wrapped their spacers in plastic bags.

\section{Discussion}

We have shown that electrostatic charge on the inner surface of a plastic spacer device greatly influences the delivery of salbutamol generated by pMDIs. This is in accordance with previous studies delivering sodium cromoglycate and budesonide through a spacer [7, 8]. Electrostatic charge attracts the particles to the spacer wall and, thus, decreases drug delivery. This effect plays a major role in new spacers, which have a high electrostatic charge. This problem remains in patients old spacers albeit to a lesser extent.

Conducting materials hold no electrostatic charge. A spacer of steel should, therefore, solve the problem of reduced drug delivery due to electrostatic charge [9]. We showed in our laboratory study that the level of electrostatic charge on a plastic spacer depends on the treatment of the spacer. In previous studies, antistatic lining was used to remove the charge $[7,8]$. This may not be a useful treatment in practice. Rinsing the spacers with water, as it is generally recommended by drug companies, does not significantly reduce the charge or improve drug delivery. Adequate treatment with detergent, however, reduced or even eliminated the electrostatic charge and improved drug delivery.

When spacers with a high electrostatic charge were coated with ionic detergent, charge was eliminated for at least $24 \mathrm{~h}$. If these spacers were stored for 1 week, whether or not wrapped in a plastic bag, the charge increased but was still lower than in new, patient's old or water-rinsed spacers. Nonionic detergent was less efficient and low charge was detectable after $2 \mathrm{~h}$ of drip drying, which built up to a high level after $24 \mathrm{~h}$.
In summary, ionic detergent coating of spacers significantly improved drug delivery of particles $<6.8 \mu \mathrm{m}$. This treatment made them equivalent to spacers internally covered with conducting material. Coating a plastic spacer by an easy and cheap method using ionic detergent may avoid the need to have millions of plastic spacers worth millions of dollars replaced by new spacers of conducting material. Coating the surface with ionic detergent may build a conducting layer, which removes the charge and is, therefore, superior to coating with nonionic detergent. Household detergents usually contain a mixture of cationic, anionic and nonionic detergents [10].

Instructions by the company for cleaning the Volumatic $\AA$ specify that the spacer should be rinsed in water; however, this treatment does not remove charge. Despite the instructions, patients clean and store their spacers in a variety of ways. It is important to have uniform recommendations. We recommend, that under ideal conditions spacers should be freshly coated with ionic detergent every $24 \mathrm{~h}$. However, practically speaking, once a week may be sufficient. In addition, the spacers should be stored unwrapped.

Acknowledgement: JW was supported by a Swiss National Foundation Grant.

\section{References}

1. Kim CS, Eldridge MA, Sackner MA. Oropharyngeal deposition and delivery aspects of metered-dose inhaler aerosols. Am Rev Respir Dis 1987; 135: 157-164.

2. Konig P. Spacer devices used with metered-dose inhalers, break through or gimmick? Chest 1985; 88: 276-284.

3. Levison H, Reilly PA, Worsley GH. Spacing devices and metered-dose inhalers in childhood asthma. J Pediatr 1985; 107: 662-668.

4. Everard ML, Clark AR, Milner AD. Drug delivery from holding chambers with attached face mask. Arch Dis Child 1992; 67: 580-585.

5. Ahmed CN, Balachandran W, Barnes P. Study of an elacto-aerosol lung deposition. J Aerosol Med 1993; 6 (Suppl.) S44.

6. Cross JA. Electrification of Solids and Liquids in Electrostatics. In: Cross JA, ed. Electrostatics: Principles, Problems and Applications. Bristol, Adam Hilger, IOP, 1987; pp. 17-90.

7. O'Callaghan C, Lynch J, Cant M, Robertson C. Improvement in sodium cromoglycate delivery from a spacer device by use of an antistatic lining, immediate inhalation, and avoiding multiple actuations of drug. Thorax 1993; 48: 603-606.

8. Barry PW, O'Callaghan C. The effect of delay, multiple actuations and spacer static charge on in vitro delivery of budesonide from the Nebuhaler. Br J Clin Pharmacol 1995; 40: 76-78.

9. Bisgaard H. A metal aerosol holding chamber devised for young children with asthma. Eur Respir J 1995; 8: 856-860.

10. Underwood E. Good Manufacturing Practice. In: Russel AD, Hugo WB, Ayliffe GAJ, eds. Principles and Practice of Disinfection. Oxford, Blackwell scientific publications, 1992; pp. 275-276. 